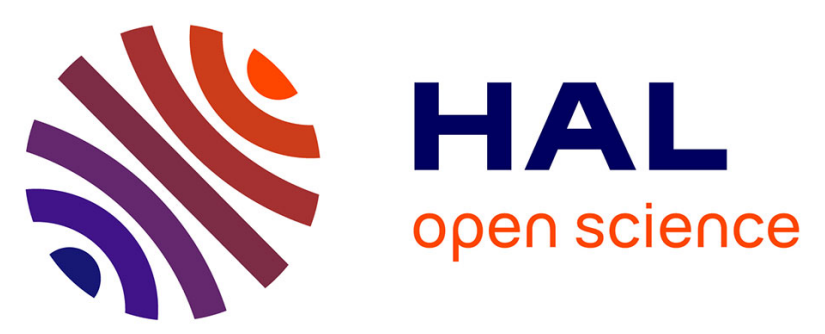

\title{
Experimental characterization of the transition region in a rotating-disk boundary layer
}

\author{
Muhammad Ehtisham Siddiqui, Benoît Pier, Julian F. Scott, Alexandre
}

Azouzi, Roger Michelet

\section{- To cite this version:}

Muhammad Ehtisham Siddiqui, Benoît Pier, Julian F. Scott, Alexandre Azouzi, Roger Michelet. Experimental characterization of the transition region in a rotating-disk boundary layer. Seventh IUTAM Symposium on Laminar-Turbulent Transition, Jun 2009, Stockholm, Sweden. pp.573-576, 10.1007/978-90-481-3723-7_103. hal-00633241

\section{HAL Id: hal-00633241 \\ https://hal.science/hal-00633241}

Submitted on 18 Oct 2011

HAL is a multi-disciplinary open access archive for the deposit and dissemination of scientific research documents, whether they are published or not. The documents may come from teaching and research institutions in France or abroad, or from public or private research centers.
L'archive ouverte pluridisciplinaire HAL, est destinée au dépôt et à la diffusion de documents scientifiques de niveau recherche, publiés ou non, émanant des établissements d'enseignement et de recherche français ou étrangers, des laboratoires publics ou privés. 


\title{
Experimental characterization of the transition region in a rotating-disk boundary layer
}

\author{
Muhammad Ehtisham SIDDIQUI, Benoît PIER, Julian SCOTT, \\ Alexandre AZOUZI, Roger MICHELET
}

\begin{abstract}
A series of experiments were performed to study the transition from laminar to turbulent flow for the boundary layer over a rotating disk and to compare with theoretical results. The mean flow profile measured in the laminar region is found to be in excellent agreement with analytical results, and the spatial growth of natural disturbances matches linear theory predictions. A hot-wire sensor was positioned at different spatial locations to determine the evolution of natural disturbances. Spectral analysis at high resolution and ensemble-averages of velocity time series have been carried out to distinguish different flow regimes.
\end{abstract}

\section{Introduction}

The flow due to a rotating disk has been used as the canonical configuration for the study of 3D boundary layers [7]. It exhibits a self-similar exact solution [1]. The basic-flow solution displays a constant boundary layer thickness $\delta=\sqrt{v / \Omega}$, where $v$ is the kinematic viscosity and $\Omega$ the disk rotation rate. Such boundary layers give rise to strong instabilities leading to the formation of cross-flow vortices, as already noticed experimentally by Gregory, Stuart and Walker [8].

Throughout this study, the axial coordinate $Z$ and radial coordinate $R$ are nondimensionalized by $\delta$. The rotating-disk flow is known to display a sharp transition from laminar to turbulent regimes at a nondimensional critical radius $R \simeq 510[7,3]$. Lingwood [2] found this transition location to precisely coincide with onset of local absolute instability at $R^{c a} \simeq 507$. More recently, a fully nonlinear analysis [4] has revealed additional aspects of primary and secondary instabilities and has further contributed to the understanding of the complex flow dynamics prevailing near the transition region.

Muhammad Ehtisham SIDDIQUI (muhammad.siddiqui@ec-lyon.fr)

Laboratoire de mécanique des fluides et d'acoustique (CNRS - Université de Lyon).

École centrale de Lyon, 36 avenue Guy-de-Collongue; 69134 Écully cedex, FRANCE. 


\section{Experimental setup}

The present rotating-disk facility consists of a glass disk, $500 \mathrm{~mm}$ in diameter, rotated at constant angular velocity $\Omega$, up to $1500 \mathrm{rpm}$ (see fig. 1 ). The maximum out-of-flatness was found to be less than 50 microns. The disk has constant angular velocity $\Omega$ to within $0.05 \%$. A high-precision two-axes traversing mechanism is used for hot-wire sensor positioning with radial and axial precisions of $20 \mu \mathrm{m}$ and $2 \mu \mathrm{m}$ respectively. The traversing mechanism and velocity measurements are controlled and recorded by a dedicated computer. A constant-temperature hot-wire anemometer is used for velocity measurements.

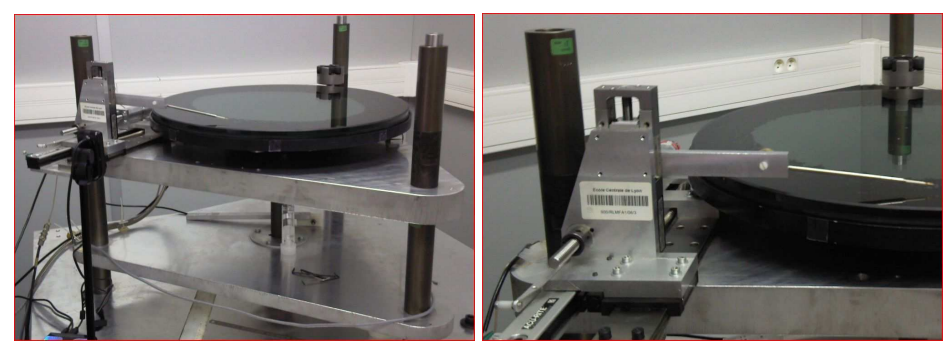

Fig. 1 Left: experimental setup consisting of a glass disk and a traversing mechanism, right: a close-up of the traversing mechanism for positioning the hot-wire probe.

\section{Mean-velocity profiles}

Circumferential mean-velocity profiles are measured at different radial locations. Fig. 2 shows measurements (symbols) obtained at $\Omega=950 \mathrm{rpm}$, plotted together with the laminar similarity profile (solid line). Velocities are nondimensionalized by $R \delta \Omega$. At the lower radii, $R \leq 470$, the measured velocity profiles are found to precisely follow the laminar profile (fig. 2a). For $490 \leq R \leq 530$ (fig. 2b), the velocity profiles are significantly different from the theoretical profile for $1<Z<4$, and $\leq 10 \%$ flow correction is observed, but the flow is not yet fully turbulent. For $R \geq 550$ (fig. 2c), a strong mean flow correction extends up to $Z=16$, this boundarylayer thickening is characteristic of a fully turbulent regime.

\section{Spectral analysis}

Fourier spectra were calculated from the azimuthal velocity time series for different radii at $Z=1,1.5,2,2.5,3,4$ and $\Omega=950 \mathrm{rpm}$ (fig. 3). At low radii $R \leq 450$, flat spectra are observed with uniform background noise level. For $R \geq 470$ and $Z \leq 2.5$, 

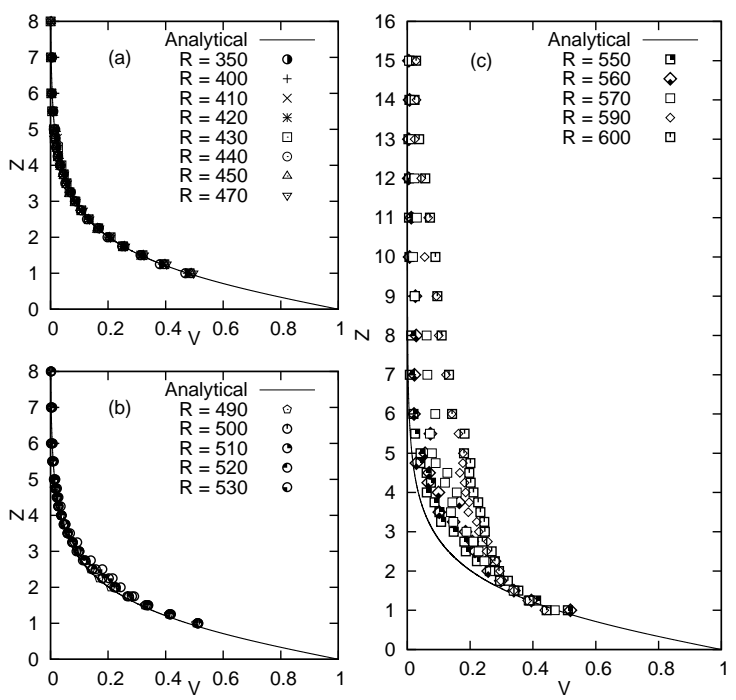

Fig. 2 Mean azimuthal velocity profiles at various radii, with $\Omega=950 \mathrm{rpm}$. (a) Laminar flow regime. (b) Weakly nonlinear regime, mean-flow corrections in the region $1<Z<4$. (c) Fully turbulent regime, strong mean-flow correction extends up to $Z=16$.

there is a band of amplified frequencies, with a maximum amplitude near $\omega / \Omega \approx$ 30. The harmonics of the fundamental frequency start to appear for $R \geq 500$, which is an indication that nonlinearities are developing. For $R \geq 530$, the harmonic peaks give way to fully developed spectra, characteristic of the turbulent regime. Further away from the disk surface, the weakly nonlinear regime is bypassed and a sudden transition from laminar to turbulent flows occurs (fig. 3c).
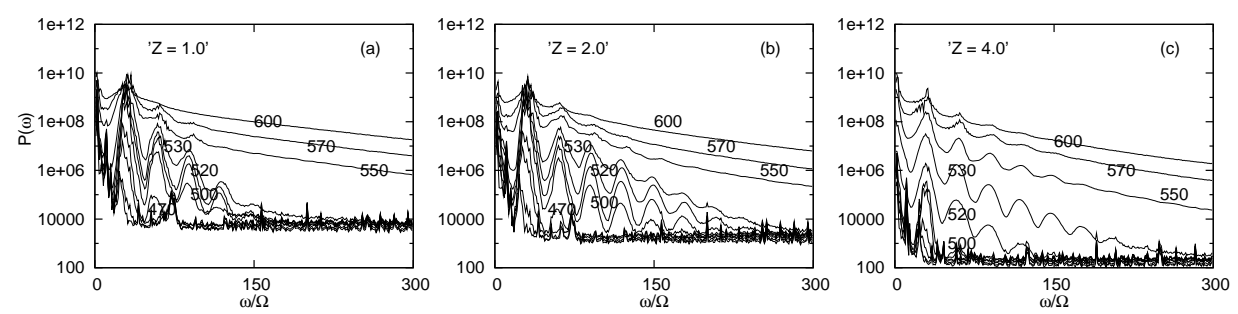

Fig. 3 Fourier power spectra for time series with $\Omega=950 \mathrm{rpm}$ at $Z=1,2,4$ and $450 \leq R \leq 600$

Fig. 4 represents high-resolution power spectra with $d \omega / \Omega=0.005$, obtained by recording time series over very long time intervals. These high-resolution spectra display the features of fig. 3 superposed with a set of discrete narrow peaks, located at every integer multiple of the disk rotation rate. The discrete part of those spectra corresponds to components of the fluctuations that have the same periodicity as the disk and that are probably stationary with respect to the disk surface. These narrow 

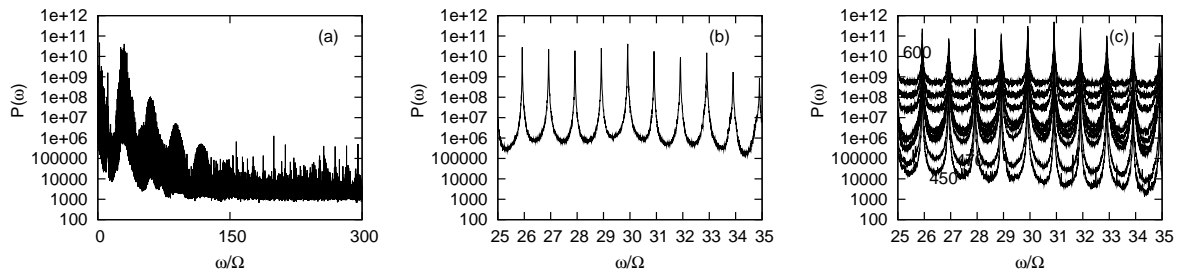

Fig. 4 High resolution power spectra with $\Omega=950 \mathrm{rpm}$ at $Z=2$ : (a) for $R=500$, (b) close-up, showing discrete spectral components. (c) for $\mathrm{R}=450,470,500,510,520,530,550,600$.

frequency peaks are particularly visible at radial locations $500 \leq R \leq 550$, where the low-resolution spectra display a weakly nonlinear harmonic regime. This discrete spectral component is not observed in the laminar boundary layer for $R<470$ and appears to be suppressed by the turbulent regime for $R \geq 550$.

\section{Conclusions and outlook}

In the present experimental study we have distinguished different flow regimes. Mean azimuthal velocity measurements have been performed and were found to follow precisely the theoretical profile in the laminar flow regime. High-resolution spectra of azimuthal velocity time series, recorded over a long duration, are found to consist of continuous and discrete parts in which the discrete part of the spectra is made up of narrow peaks with the same periodicity as the disk. Work in progress consists in implementing a new control method $[5,6]$ to modify the naturally selected flow dynamics.

This research is financially supported by the Agence nationale de la recherche (ANR, project "Microsillon").

\section{References}

1. T. von Kármán, Z. Angew. Math. Mech. 1, 232-252, 1921.

2. R. J. Lingwood, J. Fluid Mech. 299, 17-33, 1995.

3. R. J. Lingwood, J. Fluid Mech. 314, 373-405, 1996.

4. B. Pier, J. Fluid Mech. 487, 315-343, 2003.

5. B. Pier, J. Eng. Math. 57, 237-251, 2007.

6. B. Pier, Proc. R. Soc. Lond. A, 459, 1105-1115, 2003.

7. H. L. Reed and W. S. Saric, Annu. Rev. Fluid Mech. 21, 235-284, 1989.

8. N. Gregory, J. T. Stuart, W. S. Walker, Phil. Trans. R. Soc. Lond. A 248, 155-199, 1955. 